\title{
PROMOSI EVENT BUDAYA LOKAL BERBASIS PEMASARAN DIGITAL RINTISAN DESA WISATA BRANJANG
}

\author{
Tutik $^{1)}$, Heni Krisnatalia'), Y.R. Satato'), Solichoel'), Syamsul Hadi') \\ 1)Program Studi Manajemen, Sekolah Tinggi Ilmu Ekonomi Pariwisata Indonesia, Semarang, Jawa Tengah, \\ Indonesia
}

Corresponding author : Heni Krisnatalia

E-mail : heni.krisnatalia.dosen@gmail.com

\section{Diterima 09 Oktober 2021, Disetujui 25 November 2021}

\begin{abstract}
ABSTRAK
Perubahan landscape perekonomian global telah bergeser kearah teknologi digital. Oleh karena itu, dukungan atas gerakan nasional "Bangga Buatan Indonesia" dan "Gerakan Bangga Berwisata Indonesia" menuntut Kominfo bersama - sama penyelenggara platform perdagangan digital berupaya mendorong wilayah - wilayah komersial, yaitu: desa - desa atau kelurahan yang masih alpa dari $4 \mathrm{G}$ coverage signal memaksimalkan peluang dari teknologi digital melalui massive infrastructure deployment untuk Information and Communication Technology (ICT) diseluruh wilayah dan destinasi penting di Indonesia dari tahun 2021 sampai 2022 serta program pendampingan bagi UMKM dan UMi, POKDARWIS, serta DESWITA. Branjang salah satu Desa di wilayah Kabupaten Semarang sarat akan potensi wisata. Keindahan pemandangan sawah berundak/ terasering merupakan kekayaan alam yang dapat diolah menjadi produk bernilai jual. Selain itu, keberagaman budaya yang dimilikinya juga berpeluang menjadi potensi unggulan. Itulah sebabnya, dalam rangka mengangkat sejumlah potensi yang dimilikinya sebagai Rintisan Desa Wisata diperlukan upaya promosi sehingga keberadaannya dapat terekspos oleh calon wisatawan. Sementara itu, keberadaan Deswita yang tak terpisahkan oleh kehadiran UMKM sebagai penggerak kemajuan daerah wisata dan sekitarnya membuat keduanya harus jeli melihat prospek dari perubahan pada landscape perekonomian saat ini. Oleh karenanya, Tim Pengabdian STIEPARI Semarang mengadakan program pendampingan untuk mendukung percepatan digitalisasi DESWITA dan UMKM.
\end{abstract}

Kata Kunci: deswita branjang; UMKM; digital marketing; pendampingan digital marketing

\begin{abstract}
The changing landscape of the global economy has shifted towards digital technology. Therefore, the support for the national movement "Proud of Made in Indonesia" and "Proud Indonesian Traveling Movement" requires Ministry of Communication and Information Technology (KOMINFO) together with digital trading platform providers seek to encourage commercial areas, namely: villages or sub-districts which is still unreachable by $4 \mathrm{G}$ signal coverage, to enlarge opportunities from digital technology through massive infrastructure deployment for Information and Communication Technology (ICT) in all important regions and destinations in Indonesia from 2021 to 2022 as well as mentoring programs for MSMEs and UMi, POKDARWIS, and DESWITA. Branjang, one of the villages in the Semarang Regency area, is full of tourism potential. The beauty of the scenery of terraced rice fields is a natural wealth that can be processed into selling value products. In addition, its cultural diversity also has the opportunity to become superior potential. That is why, in order to raise a number of potentials it has as a Tourism Village Pioneer, promotion efforts are needed so that its existence can be exposed by potential tourists. Meanwhile, the existence of Tourism Village (DESWITA), which is inseparable from the presence of MSMEs as a driving force for the progress of tourist areas and their surroundings, makes both of them have to be observant in seeing the prospects of changes in the current economic landscape. Therefore, the STIEPARI Semarang Service Team held a mentoring program to support the acceleration of the digitization of Tourism Village (DESWITA) and MSMEs.
\end{abstract}

Keywords: branjang village, MSMEs; digital marketing; digital marketing assistance

\section{PENDAHULUAN}

Landscape perekonomian dunia telah bergeser kearah teknologi digital. Perusahaan dibidang bisnis digital berjamur mendominasi wajah pasar dunia saat ini. Oleh karena itu, dukungan atas gerakan nasional "Bangga Buatan Indonesia" dan "Gerakan Bangga Berwisata Indonesia" baik oleh Kominfo sendiri 
maupun bersama - sama dengan penyelenggara platform perdagangan digital untuk wilayah - wilayah komersial, yaitu: desa desa atau kelurahan yang masih alfa dari $4 \mathrm{G}$ coverage signal melalui massive infrastructure deployment untuk Information and Communication Technology (ICT) diseluruh wilayah dan destinasi penting di Indonesia dari tahun 2021 sampai 2022 dan program pendampingan bagi UMKM dan UMi, POKDARWIS, serta DESWITA. dalam memaksimalkan peluang teknologi digital melambangkan agility dan daya adaptasi Indonesia untuk bertransformasi dari physical space ke digital space semakin mumpuni. Tak sampai disini, Kominfo pun mengembangkan single aplikasi untuk unifikasi DESWITA, UMKM, serta Ultra Mikro (Umi) menggunakan model prototype aplikasi jaringan wisata Hub (JPHub) untuk kepentingan pariwisata dan pembangunan ekonomi secara maksimal.

Branjang merupakan salah satu Desa yang terletak di Kabupaten Semarang. Wilayah ini kaya akan potensi wisata. Selain keindahan sawah berundak/ terasering yang menjadi kekayaan sumber daya yang dapat diolah menjadi produk bernilai jual, keberagaman budaya yang ada juga dapat dikembangkan dan menjadi potensi unggulan. Itulah sebabnya, dalam rangka mengangkat sejumlah potensi yang dimilikinya sebagai Rintisan Desa Wisata diperlukan upaya dalam mempromosikan Desa Branjang sehingga keberadaannya dapat terekspos dan mampu mengundang perhatian dan minat calon wisatawan target agar berkunjung ke desa wisata tersebut.

Sementara itu, keberadaan Deswita sendiri tidak dapat dipisahkan oleh kehadiran UMKM yang merupakan aspek pendukung kemajuan daerah wisata dan sekitarnya sehingga keduanya harus jeli melihat prospek dari perubahan yang terjadi pada landscape perekonomian ini. Mengutip Alford \& Page (2015) bahwasanya adopsi teknologi guna mendukung pemasaran bagi kelangsungan usaha kecil sangatlah signifikan (Alford \& Page, 2015). Senada juga diungkapkan Setiawati \& Widyartati (2017) yang menyatakan adanya pengaruh positif dari penggunaan strategi pemasaran online terhadap peningkatan Net Profit Margin (NPM) UMKM. Kemutakhiran teknologi digital dan internet diharapkan mampu lebih cepat mendongkrak perkembangan UMKM agar naik tingkat. Pelaku bisnis harus mengubah pola pemasaran mereka mengikuti perkembangan dan kemajuan teknologi di masyarakat agar mampu bertahan hidup (Kurniawan \& Asharudin, 2018. Terlebih lagi, dengan banyak bermunculannya startup yang berupaya membantu usaha kecil sekarang ini seharusnya mampu membantu memperluas ruang gerak mereka dalam menjangkau target pasar. Namun pada kenyataannya, banyak tantangan dilapangan yang dihadapi pelaku UMKM yang kemudian menjadi hambatan bagi mereka untuk dapat bertumbuh dengan baik. Itulah mengapa seringkali upaya yang mereka lakukan menuai kegagalan dalam waktu singkat. Salah satu tantangan yang mereka hadapi menurut Cant \& Wiid (2016) diantaranya berkaitan dengan praktik marketing dan produknya. Senada juga dinyatakan Permana (2017) yang mengemukakan peran strategis UMKM dalam geliat perekonomian Indonesia menyusul kontribusi besar yang diberikannya bagi pembentukan PDB. Selain itu, sektor inipun turut andil dalam mengatasi berbagai permasalahan sosial yang tampil dimasyarakat, seperti: pengentasan kemiskinan dan pengangguran.

Keinginan yang kuat tidak diimbangi dengan kecakapan yang memadai. Kurangnya pengetahuan tentang digital marketing membuat UMKM tidak banyak mengikuti perkembangan digital (Alford \& Page, 2015; Taiminen \& Karjaluoto, 2014). Kendati, sejumlah pelaku usaha percaya bahwa penggunaan online marketing dan media sosial cukup efektif, namun sebagian besar UMKM belum sepenuhnya mampu memanfaatkan potensinya secara optimal. Taiminen \& Karjaluoto (2014) mengemukakan perlunya program pelatihan dan dukungan dari pemerintah untuk membantu UMKM mengeksploitasi digitalisasi untuk membantu mereka bertumbuh.

Menyikapi masalah tersebut, pendekatan strategis dan keterlibatan berbagai pihak sangat dibutuhkan. Kerjasama perlu dilakukan oleh para stakeholder terkait, seperti dipaparkan Slamet dkk (2017) melalui kolaborasi model Penta Helix atau multiunsur subjek atau stakeholder pariwisata yang tergabung kedalam kelompok Akademisi, Bisnis, Komunitas, Pemerintah, serta Media yang disingkat "ABCDGM".

Sejauh ini pihak pengelola Desa Wisata Branjang sendiri telah berupaya mengkomunikasikan keberadaan destinasi wisata tersebut kepada khalayak dengan tujuan menarik minat masyarakat berkunjung sekaligus menjadikannya salah satu tujuan wisata unggulan nasional yang cukup dilirik oleh masyarakat internasional kedepannya melalui sejumlah media, baik media konvensional, yaitu: brosur maupun media sosial, seperti: Web, IG, FB, Youtube, serta melalui Community Based Tourism (CBT) atau 
Jejaring Desa Wisata (Jadesta) dengan bantuan admin media sosial. Akan tetapi, Pengelola media sosial mengakui segala bentuk informasi yang terkait webiste dan instagram diperoleh secara mandiri tanpa ada pelatihan sebelumnya. Segala kendala yang dialami oleh pengelola ditindak lanjuti sesuai dengan pengetahuan mereka yang terbatas. Oleh karenanya, Tim Pengabdian STIEPARI Semarang menggandeng Humas Pengelola Desa Wisata Branjang, yang diketuai oleh Pak Yoga Adya sebagai mitra dalam pelaksanaan kegiatan Pengabdian kepada Masyarakat (PKM) ini.

Berdasarkan survey yang dilakukan dilapangan dan tatap muka secara langsung dengan perangkat desa setempat diketahui bahwa selain belum memadainya kesiapan menangani pemenuhan order fulfillment (pemesanan pemenuhan), platform rintisan digital yang dimiliki belum terkelola dengan baik. Banyak produk wisata dan UMKM yang belum diangkat kedalam platform tersebut sehingga perlulah kiranya diadakan program pendampingan berupa penyiapan materi promosi melalui penataan ulang konten dalam rangka event budaya lokal bagi rintisan Desa Wisata Branjang dan pembuatan promosi di beberapa media digital: Web, IG, Facebook maupun Youtube.

Selanjutnya, melalui merek yang ada, keunikan dikemas kedalam media promosi berbasis digital, baik Web, IG, Facebook maupun Youtube. Diharapkan dengan event yang menjadi target utamanya, maka semua potensi pariwisata yang unik dan bernilai jual di Desa Branjang dapat ditampilkan melalui media digital tersebut.

\section{METODE}

Kegiatan pengabdian ini berlangsung selama bulan Maret sampai Agustus 2021 di Desa Branjang. Sementara, proses pelaksanaannya dilakukan di tengah suasana pandemi COVID-19 dengan pemberlakuan prosedur prokes $3 \mathrm{M}$ serta disiplin diri mulai dari pemakaian masker, menjaga jarak, serta penggunaan hand sanitizer sebelum memasuki tempat pelatihan.

Metode yang diterapkan pada pelatihan ini berupa ceramah dan simulasi dengan praktek langsung seperti halnya kegiatan serupa yang dilaksanakan oleh (Dewi \& Handayani, 2020) pada masa pandemi Metode ceramah mencakup penjelasan materi terkait, diskusi, serta tanya jawab. Sedangkan, tahapan metode dalam pelaksanaan pelatihan adalah sebagai berikut:

a. Ceramah dan Tanya jawab oleh Syamsul Hadi, S.Pdl. MM untuk melakukan identifikasi media promosi yang dimiliki oleh Desa Branjang untuk membedah permasalahan yang dihadapi.

b. Demonstrasi dan praktek untuk penyusunan ulang konten promosi Web, IG, FB dan Youtube" oleh Tutik, S.Pd., M.Si. untuk memberikan gambaran konkrit serta penjelasan bagaimana cara mengelola dan mengembangkan konten promosi melalui platform tersebut.

c. Ceramah dan Tanya jawab oleh Solichoel, S.Kom, M.M.Par. yang mengupas seluk beluk E-Business, melalui pengenalan dan demonstrasi penjualan berbasis cloud untuk membantu meningkatkan produktivitas dan daya saing bisnis

d. Demonstrasi dan praktek simulasi pemesanan paket wisata oleh Yuniarto Rahmad Satato, S.E., M.M., M.Si. mengetahui tahapan dalam membuat perencanaan paket wisata

e. Heni Krisnatalia, S.S., M.MPar, melalui metode bermain peran (role playing) melakukan simulasi pemasaran daerah tujuan wisata dan produk UMKM dimana peserta mengambil peran dalam suatu situasi tertentu seperti persiapan menghadapi kondisi - kondisi serupa.

Alur dan metode kegiatan dapat dilihat pada Gambar 1.

\section{HASIL DAN PEMBAHASAN}

Kegiatan pelatihan dilaksanakan pada bulan Maret sampai dengan Agustus 2021 dan diikuti oleh para pelaku UMKM dan aparatur Desa Branjang.

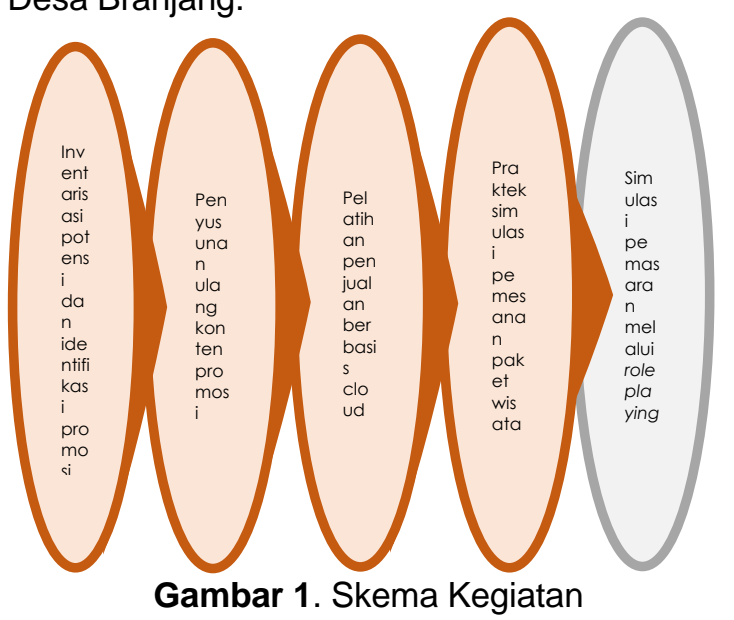

Sebelum kegiatan pelatihan digelar, tim pelaksana berkunjung ke lokasi untuk mengurus perizinan dan melakukan kajian teknis/ tinjauan lapangan sekaligus menentukan waktu dan lokasi pelaksanaan kegiatan di Desa Branjang pada Sabtu, 6 Maret 2021. (Gambar 2) 




Gambar 2. Perijinan dan kajian teknis/ tinjauan lapangan

Selanjutnya, proses perijinan dan kajian teknis/ tinjauan lapangan diikuti dengan acara diskusi bersama menggunakan metode pendekatan Focus Disscusion Group (FGD) pada Sabtu, 17 Juli 2021 untuk melakukan pengkajian dan inventarisasi masalah potensi desa wisata dan UMKM secara daring (online) melalui aplikasi Zoom (Gambar 3)

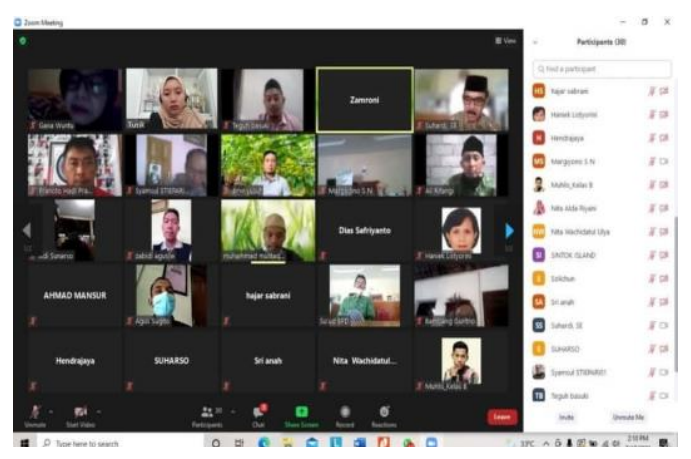

Gambar 3. FGD secara daring (online)

Berdasarkan pengkajian dan inventarisasi permasalahan yang dilakukan diperolehlah sejumlah temuan yang dapat dirinci sebagai berikut:

Tabel 1. Data Potensi Desa Wisata Branjang

\begin{tabular}{|c|c|c|c|c|}
\hline No & $\begin{array}{l}\text { Jenis } \\
\text { Atrak } \\
\text { si } \\
\text { Wisat } \\
\text { a }\end{array}$ & $\begin{array}{l}\text { Bentuk } \\
\text { Atraksi }\end{array}$ & $\begin{array}{l}\text { Juml } \\
\text { ah }\end{array}$ & Keterangan \\
\hline A & ALAM & & & \\
\hline 1. & $\begin{array}{l}\text { Securug } \\
\text { / Sigandu }\end{array}$ & $\begin{array}{l}\text { Air } \\
\text { Terjun }\end{array}$ & $\begin{array}{l}1 \\
\text { desti } \\
\text { nasi }\end{array}$ & $\begin{array}{lr}\text { Belum } & \text { terkelola } \\
\text { dengan } & \text { baik, } \\
\text { masih } & \text { menjadi } \\
\text { tempat } & \text { pembua } \\
\text { ngan } & \end{array}$ \\
\hline 2. & $\begin{array}{l}\text { Sun } \\
\text { set } \\
\text { Sedan } \\
\text { dang }\end{array}$ & $\begin{array}{l}\text { Spot } \\
\text { Selfie }\end{array}$ & $\begin{array}{l}1 \\
\text { desti } \\
\text { nasi }\end{array}$ & $\begin{array}{l}\text { Akses jalan } \\
\text { dan infrastruktur } \\
\text { wisata } \\
\text { Belum terkonsep }\end{array}$ \\
\hline 3. & $\begin{array}{l}\text { Sawah } \\
\text { Berun } \\
\text { dak/ } \\
\text { Terase } \\
\text { ring }\end{array}$ & $\begin{array}{l}\text { Spot } \\
\text { Selfie }\end{array}$ & $\begin{array}{l}1 \\
\text { desti } \\
\text { nasi }\end{array}$ & $\begin{array}{l}\text { Belum terkelola } \\
\text { dengan baik, } \\
\text { akses jalan belum } \\
\text { tertata }\end{array}$ \\
\hline
\end{tabular}

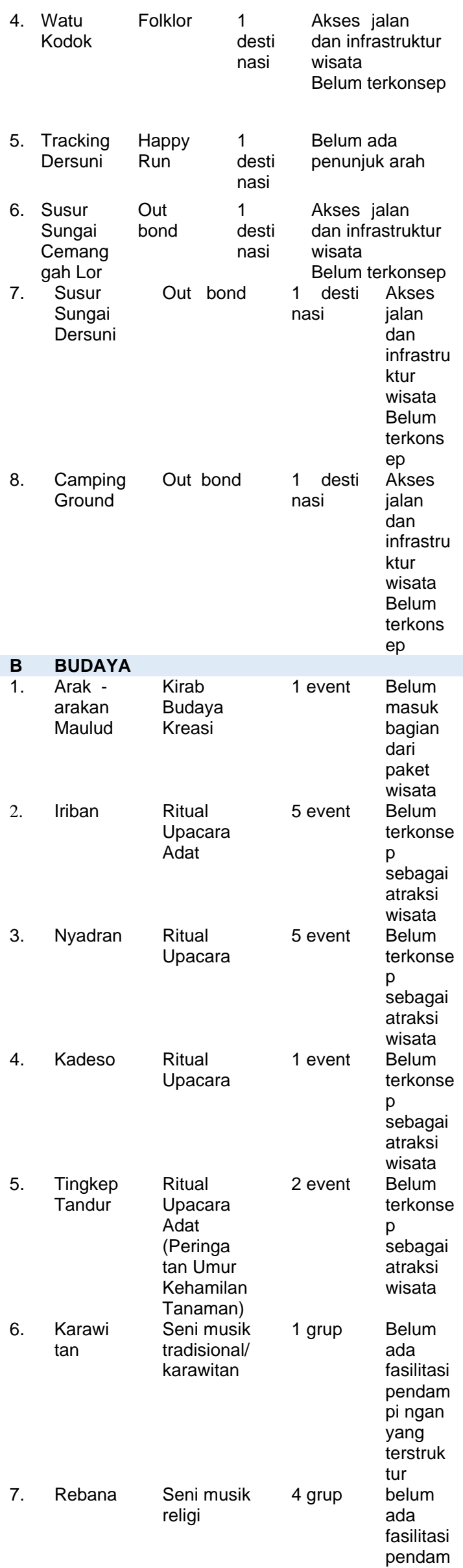




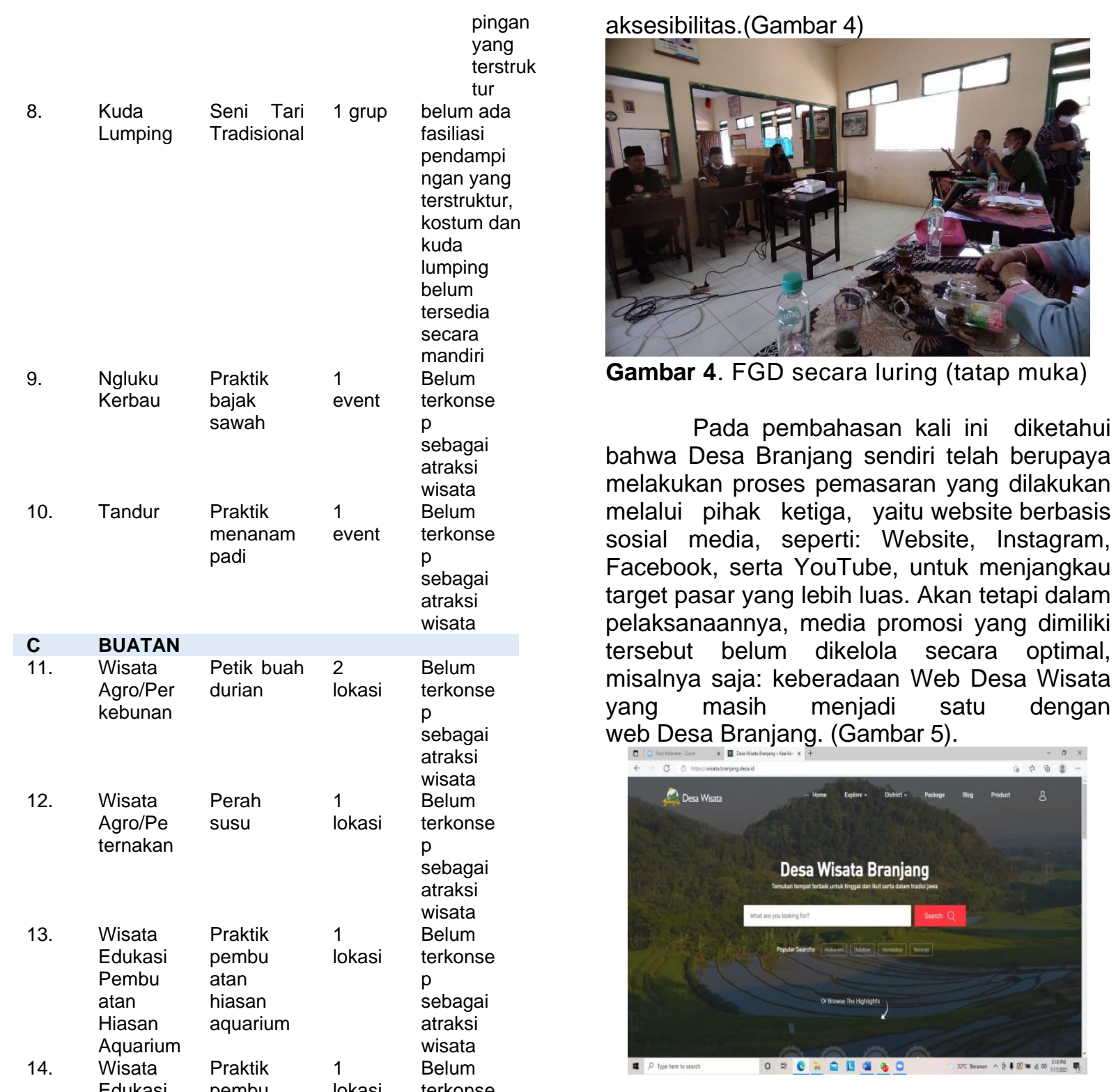

Gambar 5. Web Desa Wisata menjadi satu dengan Web Desa Branjang

Selain itu konten yang dipromosikan juga masih terbatas dan belum memiliki informasi yang lengkap perihal konten yang dipublish. (Gambar 6)

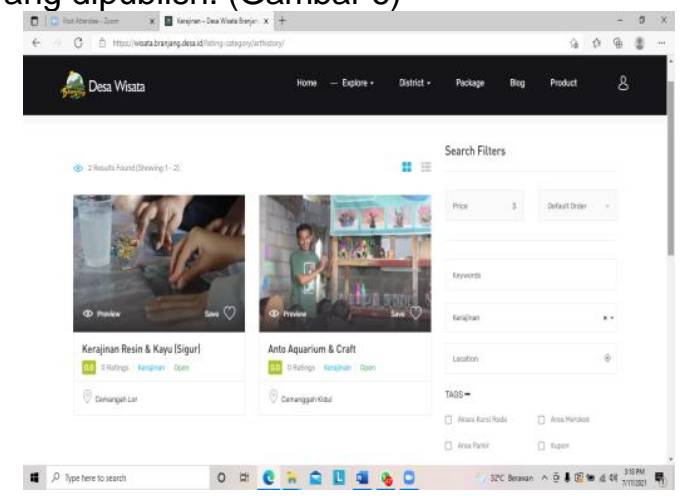

Gambar 6. Konten masih terbatas dan belum memiliki informasi lengkap perihal konten yang dipublish. 
Sementara itu, pelaksanaan kegiatan pelatihan, dimulai pada Rabu, 11 Agustus 2021. Pelatihan ini diawali dengan pembukaan acara oleh Yuniarto Rahmad Satato, S.E., M.M., M.Si. selaku ketua tim pelaksana pengabdian yang diikuti sejumlah arahan untuk memetakan langkah pembinaan yang akan dilakukan.

Acara kemudian dilanjutkan dengan memasuki materi pertama pelatihan, yaitu: melakukan identifikasi media promosi untuk membedah permasalahan yang dihadapi dalam mengembangkan potensi wisata dan produk UMKM desa Branjang agar lebih efektif dan efisien menjangkau target sasaran, diantaranya melalui pemisahan Web Desa Branjang yang memuat profile desa dengan Web Desa Wisata sebagai saluran media promosi, penyusunan ulang konten media promosi, dan cloud computing. (Gambar 7)

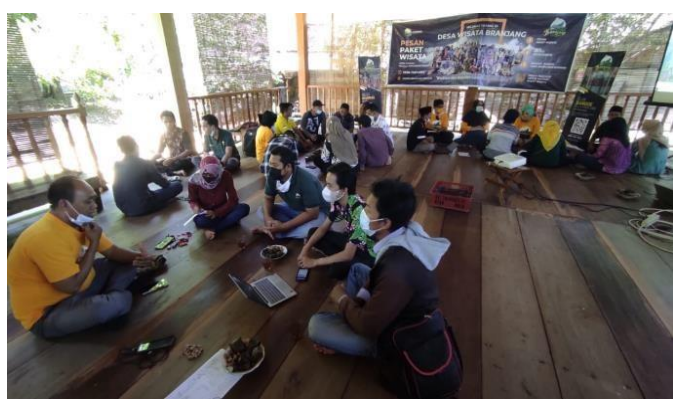

Gambar 5. Identifikasi Media Promosi

Pada materi pelatihan kedua dilakukan demonstrasi dan praktek penyusunan ulang promosi pada Website, Instagram, Facebook, dan Youtube Desa Branjang pada Minggu 15 Agustus 2021. Hal ini penting dilakukan karena media sosial tersebut sangat akrab dengan generasi milenial sehingga kedepan, harapannya akan lebih mudah menyebarluaskan promosi dan mampu menjangkau target yang lebih luas lagi. (Gambar 8)

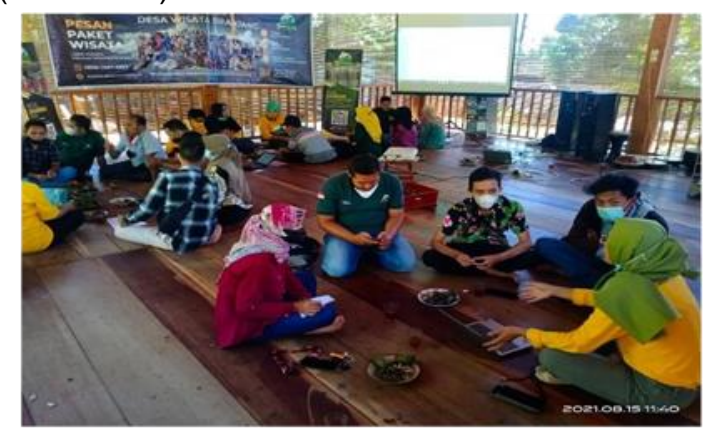

Gambar 8. Penyusunan Ulang Konten Promosi

Pembenahan dilakukan mulai dari pemisahan antara Web Desa dan Web Desa Wisata yang merupakan saluran promosi wisata Desa Branjang. (Gambar 9 dan Gambar 10)

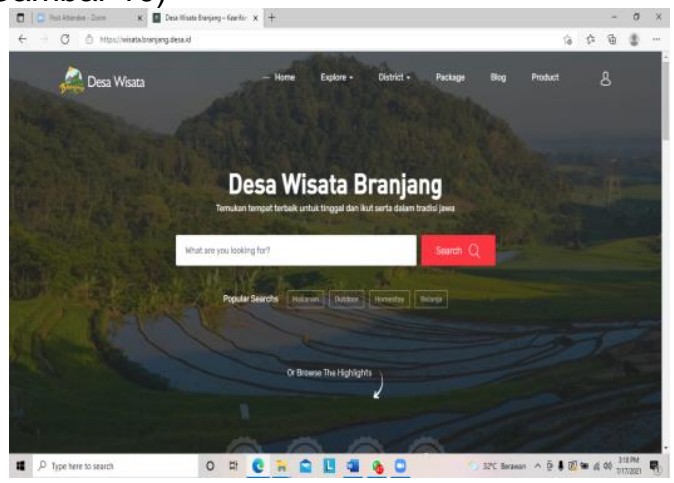

Gambar 9. Web Desa Branjang

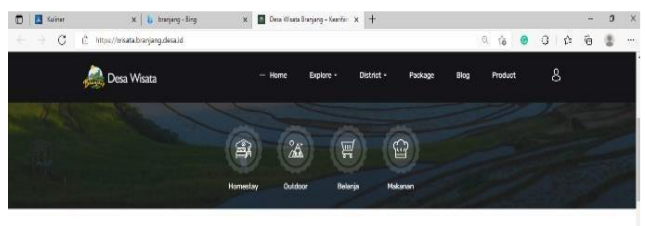

Apayang Berbeda?

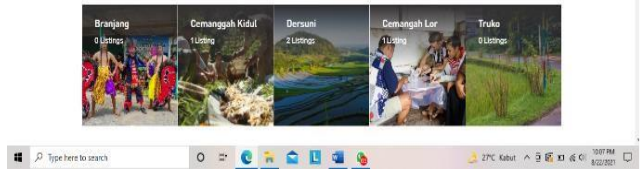

Gambar 10. Web Desa Wisata Branjang

Setelah pemisahan situs web selesai, dilakukanlah kegiatan untuk melengkapi konten Instagram yang semula hanya terdapat 3 foto dan terkesan tidak menarik sebagai media promosi. (Gambar 11 dan Gambar 12)

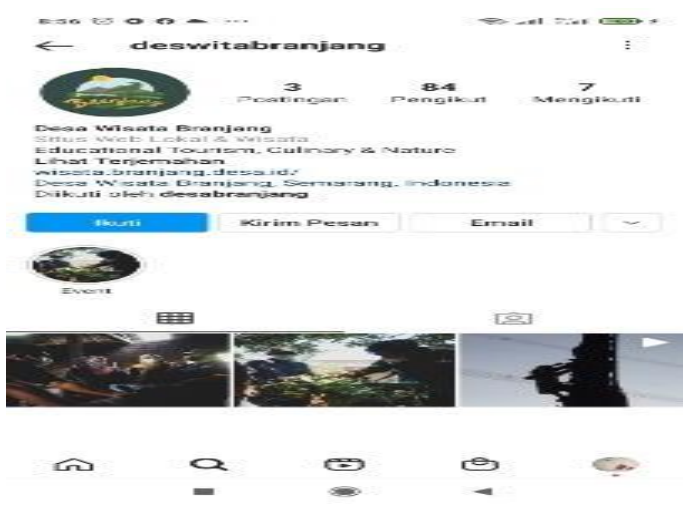

Gambar 11. Konten Promosi Instagram hanya memuat 3 foto 


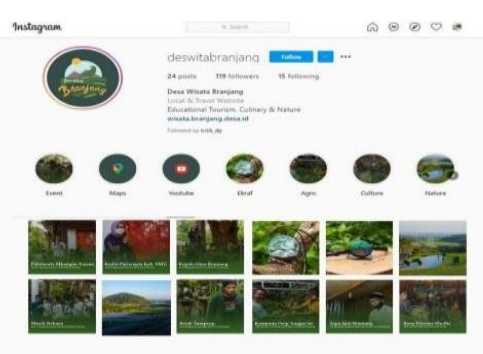

Gambar 12. Konten Instagram memuat foto yang lebih lengkap dan memadai

Pembenahan kemudian beranjak pada media promosi Youtube yang dipandang kurang lengkap dalam mengangkat potensi yang dimiliki Desa Branjang. (Gambar 13 dan Gambar 14)

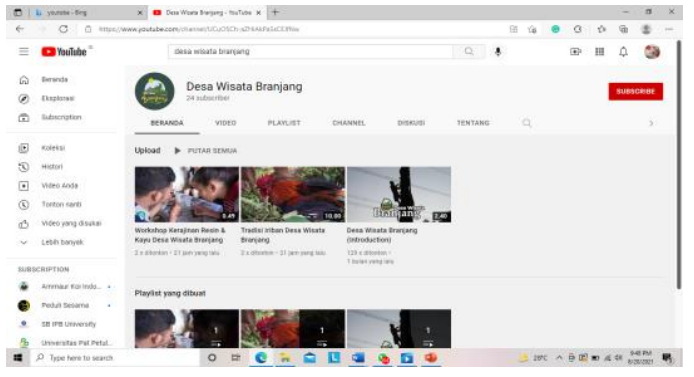

Gambar 13. Konten Video yang dipublish belum lengkap menampilkan potensi yang dimiliki.

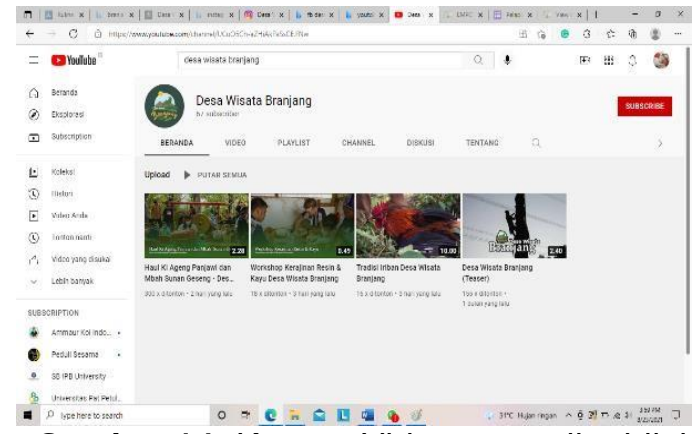

Gambar 14. Konten Video yang dipublish lebih lengkap menampilkan potensi yang dimiliki.

Menginjak materi ketiga, dilakukan pengenalan dan demonstrasi Cloud Computing pada Minggu, 15 Agustus 2021 dimana diharapkan pihak pengelola Desa Wisata Branjang dapat memanfaatkan media Cloud sebagai penunjang dalam penjualan potensi dan produk wisatanya dan kedepannya mampu memberikan kemudahan calon wisatawan dalam mendapatkan informasi terkini mengenai potensi dan produk wisata Desa Branjang. (Gambar 15)

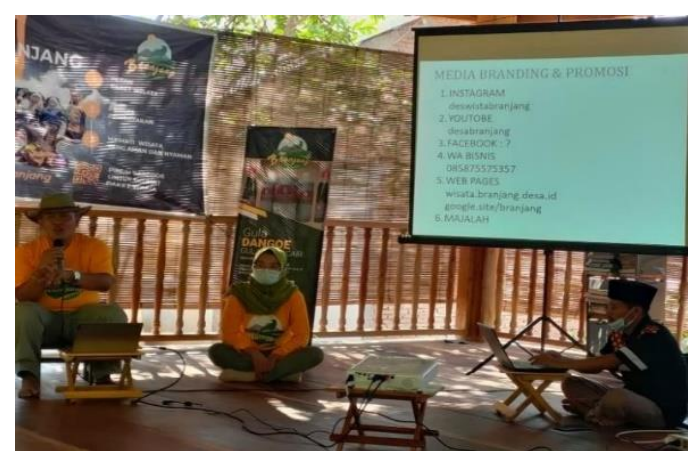

Gambar 15. Pengenalan dan Demonstrasi Penjualan Berbasis Cloud

Materi berikutnya dilanjutkan dengan praktik simulasi pemesanan paket wisata baik melalui website maupun instagram pada Senin, 16 Agustus 2021 sampai Rabu, 18 Agustus 2021

Simulasi ini dimaksudkan sebagai uji coba keefektifan media sosial sebagai media untuk pemesanan paket wisata yang setelah dilakukannya pembenahan sehingga masyarakat yang berminat berkunjung ke Desa Wisata Branjang dapat memesan paket wisata melalui web yang telah tersedia terlebih dahulu dimana web tersebut nantinya akan terhubung dengan berbagai media sosial yang dimilikinya. (Gambar 16 dan 17)



Gambar 16. Simulasi pemesanan melalui website
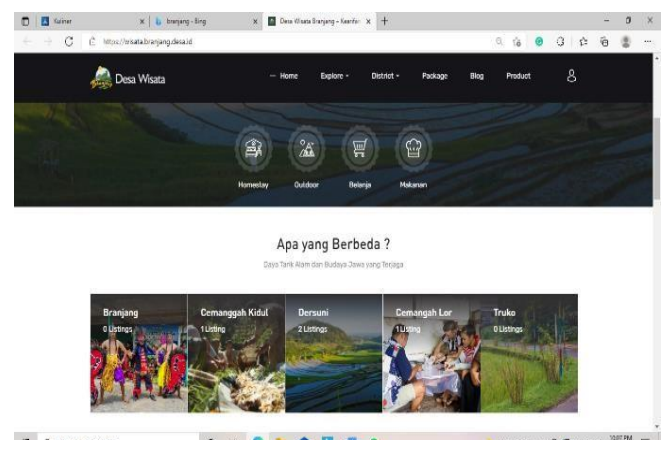

Gambar 17. Simulasi pemesanan melalui instagram 
Pada penghujung acara dilakukan model pembelajaran bermain peran (Role Playing) melalui Acara Gelar Event Budaya Lokal pada Kamis, 19 Agustusi 2021 (Gambar 18 dan Gambar 19)

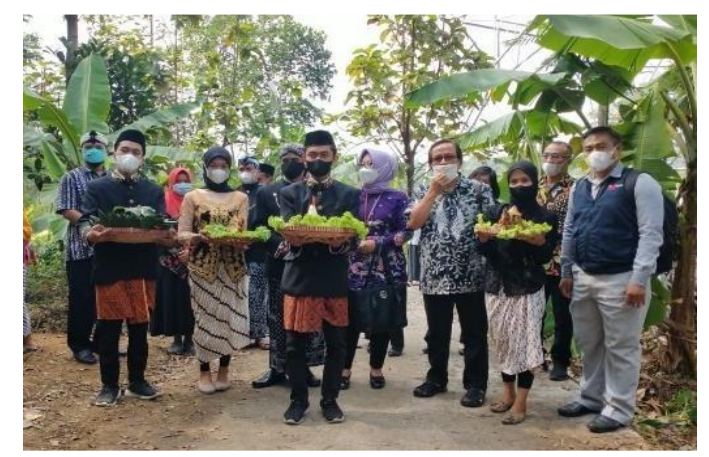

Gambar 18. Role Playing pada Gelar Event

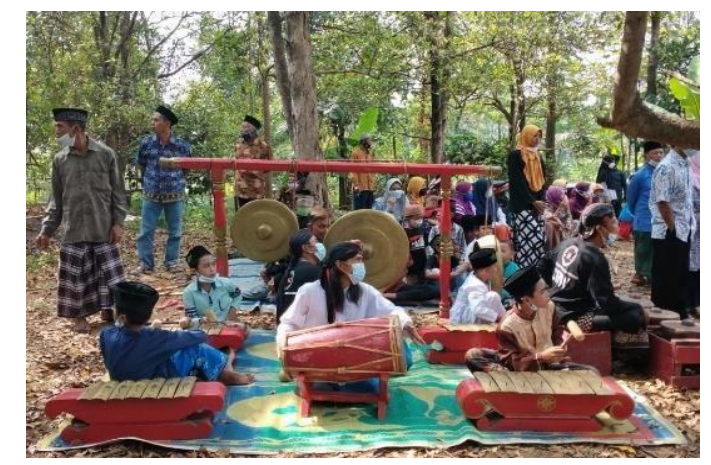

Gambar 19. Role Playing pada Gelar Event Budaya Lokal

Pada sesi ini tim pelaksana
berkolaborasi dengan masyarakat
setempat dalam pengemasan
acara gelar event budaya lokal menjadi
paket wisata religi untuk ditawarkan
kepada wisatawan.

\section{SIMPULAN DAN SARAN}

Kegiatan pengabdian masyarakat ini memperlihatkan hasil yang cukup signifikan dimana para pelaku UMKM Desa wisata Branjang dapat mengikuti pelatihan dengan baik dan langsung dapat mempraktekkan materi yang dibuktikan dengan semakin menarik dan lengkapnya wajah website, instagram, youtube, dan role playing acara gelar event budaya lokal yang dikemas menjadi salah satu paket wisata religi yang ditawarkan setelah dilakukannya pembenahan dan penataan ulang selama berlangsungnya penyampaian materi.

Kegiatan ini diharapkan mampu memperluas wawasan masyarakat tentang digital marketing serta pemahaman terhadap seluk - beluk konsep digital marketing dalam rangka mempromosikan event budaya lokalnya yang pada kelanjutannya mampu mendongkrak popularitas Desa wisata Branjang sebagai salah satu daerah tujuan wisata (DTW) pilihan selain menjangkau calon wisatawan target untuk berkunjung ke lokasi.

\section{UCAPAN TERIMAKASIH}

Kami mengucapkan terima kasih yang sebesar - besarnya kepada seluruh civitas akademika Sekolah Tinggi Ilmu Ekonomi Pariwisata Indonesia (STIEPARI) Semarang), khususnya Dr. Samtono, M.Si selaku Ketua dan Dr. Andhi Supriyadi, SE., ST., MM., MH. sebagai Ketua Penelitian dan Pengabdian Pada Masyarakat (P3M), Penghargaan juga kami berikan kepada para mitra yang telah membantu terlaksananya kegiatan Pengabdian Kepada Masyarakat (PKM) bertajuk "Promosi Event Budaya Lokal Berbasis Pemasaran Digital Rintisan Desa Wisata" yang telah turut berkontribusi secara langsung dalam sharing knowledge dan diskusi seputar Promosi Event melalui pemanfaatan teknologi digital serta para pelaku UMKM Deswita Branjang.

\section{DAFTAR RUJUKAN}

Alford, P \& Page, S.J (2015) Marketing technology for adoption by small business. The Service Industries Journal, 2015 Vol. 35, Nos. 11-12.

Cant, M.C \& Wiid, J.A (2016). The use of traditional marketing tools by SMEs in an emerging economy: a South African perspective. Problems and Perspectives in Management, Volume 14, Issue 1,2016

Permana, S.H (2017) Strategi Peningkatan Usaha Mikro, Kecil dan Menengah (UMKM) di Indonesia. Aspirasi Vol. 8 No. 1, Juni 2017

Setiawati, I \& Widyartati, P (2017) Pengaruh Strategi Pemasaran Online Terhadap Peningkatan Laba UMKM. Seminar Nasional dan Call for Paper 2017 Strategi Pengembangan Sumber Daya Manusia Melalui Publikasi Jurnal IImiah dalam Menyikapi Permenristekdikti RI No.20 Tahun 2017

Suharto, E (2005). Membangun Masyarakat Memberdayakan Rakyat. Bandung: Refika Aditama, 2005.

Taiminen, H.M \& Karjaluoto, H (2014). The usage of digital marketing channels in SMEs. Journal of Small Business and Enterprise Development Vol. 22 No. 4, 2015, pp. 633-651 